\title{
Reproductive Characteristics and Nutritional Status of Coastal Women
}

\author{
Nuruzzaman ${ }^{1 *}$ \\ Md Ashraful Alam² \\ Md Parvez lqbal Sharif ${ }^{3}$ \\ Parveen Akter ${ }^{4}$ \\ Nabeela Mazid ${ }^{5}$ \\ Shah Niaz Md Rubaid Anwar \\ 'Nandail Upazila Health Complex \\ Mymansing, Bangladesh.
}

${ }^{2}$ Department of Maternal and Child Health National Institute of Preventive and Social Medicine (NIPSOM) Dhaka, Bangladesh.

${ }^{3}$ Department of Community Medicine Chattagram Maa-O-Shishu Hospital Medical College Chittagong, Bangladesh.

${ }^{4}$ Population Services and Training Centre Dhaka, Bangladesh.

${ }^{5}$ Medical Officer (Former)

Chattagram Maa Shishu-O-General Hospital Chittagong, Bangladesh.

${ }^{6}$ Marie Stopes Clinic Dhaka, Bangladesh.

*Correspondence to:

\section{Dr. Nuruzzaman}

Medical Officer

Nandail Upazila Health Complex

Mymansing, Bangladesh.

Mobile : +8801717443467

Email: nuruzzamansakil@gmail.com

http://www.banglajol.info/index.php/CMOSHMCJ

\begin{abstract}
Women are more vulnerable in health and family planning and this vulnerability is more in-depth in coastal area. The study was done to determine the reproductive characteristics and nutritional status of women in coastal area. It was conducted in Moheshkhali upazila of Cox's Bazar district in 2013 among 220 purposively selected coastal women of reproductive age. Face to face interview was done through pretested questionnaire. Average age of the respondents was 26.5 years. Almost $60 \%$ of them were Muslims and $44 \%$ were illiterate. The average monthly family income and family size was Tk-6968.18 and 5.8 respectively. More than half $(56 \%)$ of the respondents had history of regular use of contraceptives and oral pill was the most common type of contraceptive. Average number of children was 2.95. More than half of them (54\%) had history of home delivery. More than one-third (34\%) of them were under nourished. Nutritional status was significantly associated with income $(p<0.05)$. Majority of them got early marriage $(70 \%)$ but early marriage was not significantly associated with their nutritional status. Age at first pregnancy and parity of the respondents were in significant state with the nutritional status of women of coastal area $(p<0.05)$. Socio-demographic disparity should be reduced to improve the nutritional status by improving the reproductive health of coastal women.
\end{abstract}

Key words: Early marriage; Nutritional status; Socio-economic disparity; Coastal area.

\section{INTRODUCTION}

Over the last three decades the world has witnessed a dramatic change in reproductive behavior of women in Bangladesh. The Total Fertility Rate (TFR) has dropped dramatically from a high level of 6.3 births per woman in the mid-1970s to 3.00 births in 2004. Meanwhile, the Contraceptive Prevalence Rate (CPR) has increased from a low level of $7.7 \%$ to a high level of $61.2 \%$. These achievements in reproductive behavior of Bangladeshi women have been viewed as 'success in a challenging environment'. However, these average pictures hide the wide variations in reproductive behavior that are prevailing across regions and subgroups of women by socioeconomic strata. One such region is coastal area ${ }^{1}$. This challenging environmental condition also makes there nutritional status more vulnerable. This study was undertaken to describe the reproductive characteristics of coastal women of reproductive age and to find out its impact on and nutritional status. Women of reproductive age are defined by the World Health Organization (WHO) as someone within 15-49 years of age. Family planning program and use of contraceptives have no doubt effect directly on fertility of women. If family planning program served most women with unmet need, the demographic impact would be substantial contraceptive prevalence would rise, reducing fertility and population growth ${ }^{2}$. Currently more than half of the pregnancies in the world are unintended- that is they occurs too soon, too close together. Consequently many women give birth more then they want or can care for, and other turn to unsafe abortion. Maternal and infant mortality are unacceptably high, especially among disadvantaged women- those who are poor, live in rural areas or have little education ${ }^{3}$. 
Another important factor is the economic status and living condition of individuals. A change in income will change the desire family size ${ }^{4}$. On the basis of preliminary findings from 1991 Population Census, the 1981-1991 per anum population growth rate $2.17 \%$. If this rate continues, the population of Bangladesh will double in the next 32 years to roughly 224 million, aggravating further the existing population density ${ }^{5}$. The people among the coastal belt area are the most vulnerable for any kind of natural disaster like cyclone, flood etc. Life style, custom, norms, belief etc. are totally different as because they have to fight with this atypical challenging environmental condition. Lack of life security, food security, huge losses of assets make them think a bit differently. As there is increase chance of death due to any natural disaster so they might be used to take many children. Beside these, as this coastal area is hard to reach area, family planning and other reproductive health services are supposed to be not easier to get.

\section{MATERIALS AND METHODS}

This cross sectional study was conducted among the coastal women of reproductive age group of Moheshkhali upazila of Cox's Bazar district to find out the reproductive characteristics and nutritional status of women in coastal area. Data were collected through face to face interview of 220 women of reproductive age using a semi-structured questionnaire. Before starting the procedure informed consents were taken properly and data were collected maintaining privacy as much as possible. Nutritional status was measured by BMI and categorized according to WHO guideline. Reproductive characteristics were described by age at marriage, age at first pregnancy, contraceptive use and parity. Data processing and analyses were done using SPSS (Statistical Package for Social Sciences) version 16. Ethical permission was obtained from the Ethical Committee of National Institute of Preventive and Social Medicine (NIPSOM).

\section{RESULTS}

This cross-sectional study was carried out among 220 married women of reproductive age in coastal area. Majority of the respondents $(78 \%)$ were within 21 to 30 years and average age was 26 years with \pm 6.09 years Standard Deviation (SD). Almost half of them (48\%) were income group of 5001 10000 taka. There average income was $6968.18 \mathrm{Tk}$. More than $40 \%$ had at least five family members. Women were more literate. Majority of them 193 (88\%) were house wives. Almost half of the husbands were fisherman 104 (47\%). More than half of them were Muslims and lived in nuclear family. Kacha (44\%) and tin-shed houses (47\%) were commonly found.

Average age of menarche was 12 years. About $70 \%$ had history of early marriage. There mean age at $1^{\text {st }}$ pregnancy was 18 years with standard deviation (SD) of \pm 2.60 years. Almost $60 \%$ had more than 2 children and average number of children was 2.95. More than half of them $(54 \%)$ had history of home delivery and rest of them experienced institutional delivery. Only $16 \%$ had history of caesarian section. Less than one-third $(30 \%)$ had history of complication during pregnancy.
Table 1 : Distribution of age, family income and family size

\begin{tabular}{|c|c|c|c|c|}
\hline & Character & Frequency & Percentages (\%) & Mean \pm SD \\
\hline & Age of the res & & & \\
\hline & $<20$ & 16 & 7.3 & \\
\hline & 21 to 30 & 172 & 78.2 & $26.5 \pm 6.1$ \\
\hline & $>31$ & 32 & 14.5 & \\
\hline . & Age of the hus & & & \\
\hline$\frac{2}{0}$ & $\leq 21$ & 2 & 0.9 & \\
\hline$\ddot{q}$ & $21-35$ & 154 & 70 & $33.4 \pm 7.8$ \\
\hline త్ర & $\geq 35$ & 64 & 29.1 & \\
\hline 0 & Monthly fami & & & \\
\hline 를 & $\leq 5000$ & 92 & 41.8 & \\
\hline b & $5001-10000$ & 106 & 48.2 & $6968 \pm 33-49$ \\
\hline : & $\geq 10001$ & 22 & 10 & \\
\hline$\underline{1}$ & Family size & & & \\
\hline$\frac{9}{8}$ & $\leq 4$ & 67 & 30.5 & \\
\hline n & 5 to 6 & 93 & 42.3 & $5.8 \pm .2 .3$ \\
\hline & $\geq 7$ & 60 & 27.2 & \\
\hline
\end{tabular}

Source: Survey Report

Table 2 : Distribution of reproductive characteristics of coastal women

Age at menarche

$\leq 12$

146

$>12$

74

Age at marriage (in years)

$<18$

$\geq 18$

64

$16.66 \pm 2.13$

Age at 1st pregnancy (in years)

$<20 \quad 176$

80

$\geq 20$

44

$17.85 \pm 2.60$

Age at 1st delivery

$<20$

$\leq 2$ years
$>20$

41

Number of children

$\leq 2$

91

$>2$

58.6

Average Birth spacing

109

49.5

$>2$ years

111

50.5

$17.79 \pm 2.23$

Source: Survey Report 
Table 3 : Education and family income with nutritional status of the respondents

\begin{tabular}{cccccc}
\multicolumn{5}{c}{ Nutritional status (BMI) } \\
Characteristics & $<18.5$ & $\geq 18.5$ & Total & $\chi 2$ & P value \\
& $\mathrm{n}(\%)$ & $\mathrm{n}(\%)$ & $\mathrm{n}(\%)$ & &
\end{tabular}

\section{Educational status of the respondents}

\begin{tabular}{lrrlrl} 
Illiterate & $38(39.6)$ & $58(60.4)$ & $96(100)$ & 2.69 & 0.10 \\
Literate & $36(29.0)$ & $88(71.0)$ & $124(100)$ & & \\
\multicolumn{2}{l}{ Monthly family income } & & & & \\
$\leq 5000$ & $43(46.7)$ & $49(53.3)$ & $92(100)$ & 12.16 & 0.01 \\
$>5000$ & $31(24.2)$ & $97(75.8)$ & $128(100)$ & &
\end{tabular}

Table 4 : Reproductive characteristics and nutritional status of the respondents

\begin{tabular}{|c|c|c|c|c|c|}
\hline \multirow{3}{*}{ Characteristics } & Nutrition & tus (BMI) & & \multirow{3}{*}{$x^{2}$} & \multirow{3}{*}{$P$ value } \\
\hline & $<18.5$ & $\geq 18.5$ & Total & & \\
\hline & n (\%) & n (\%) & n (\%) & & \\
\hline
\end{tabular}

Age at marriage (years)

$\begin{array}{llllll}<18 & 57(36.5) & 99(63.5) & 156(100) & 2.02 & 0.15\end{array}$

$\geq 18 \quad 17(26.6) \quad 47(73.4) \quad 64(100)$

Age at 1st pregnancy (years)

$\begin{array}{llllll}\leq 19 & 66(37.5) & 110(62.5) & 176(100) & 5.8 & 0.01 \\ >19 & 8(18.2) & 36(81.8) & 44(100) & & \end{array}$

Source: Survey Report

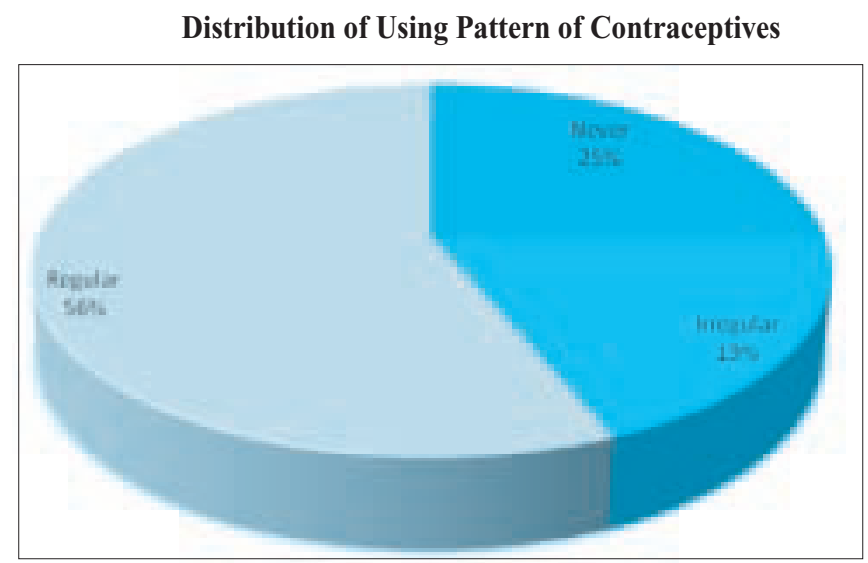

Figure 1 : Contraceptive Prevalence Rate (CPR)

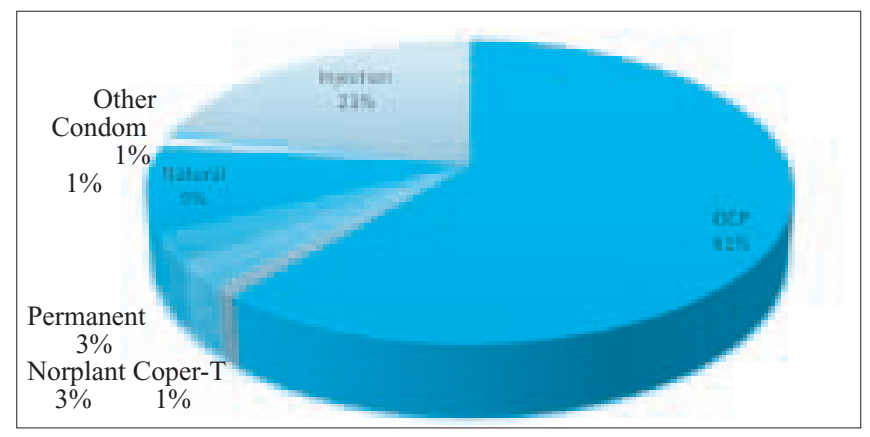

Figure 2 : Distribution of types of contraceptive

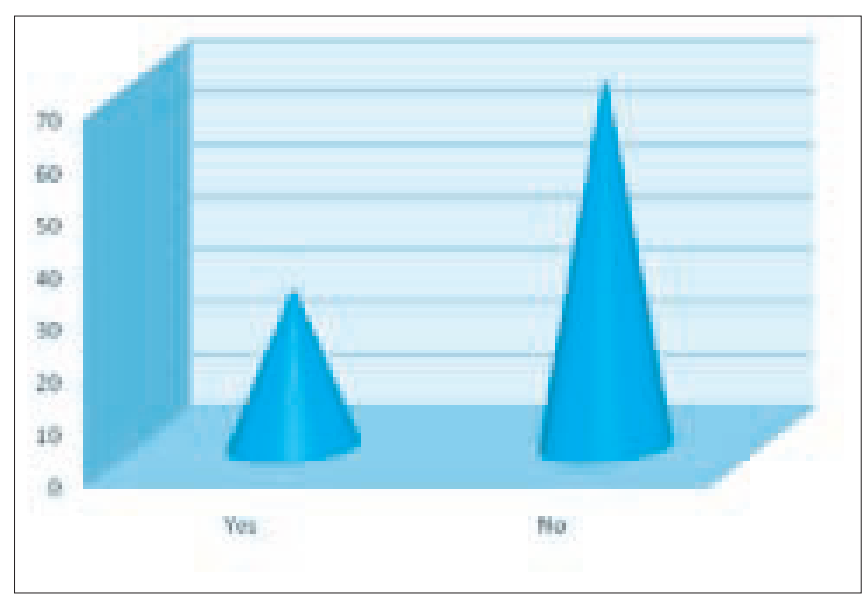

Figure 3 : Pregnancy complication

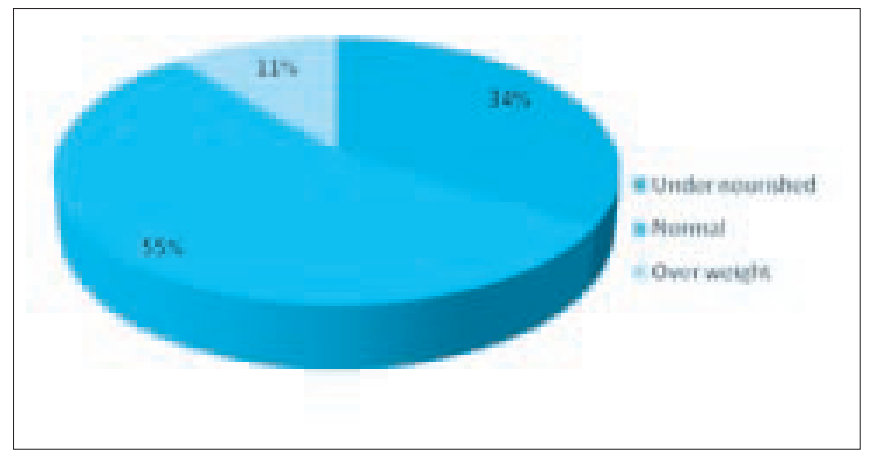

Figure 4 : Nutritional status of the respondents

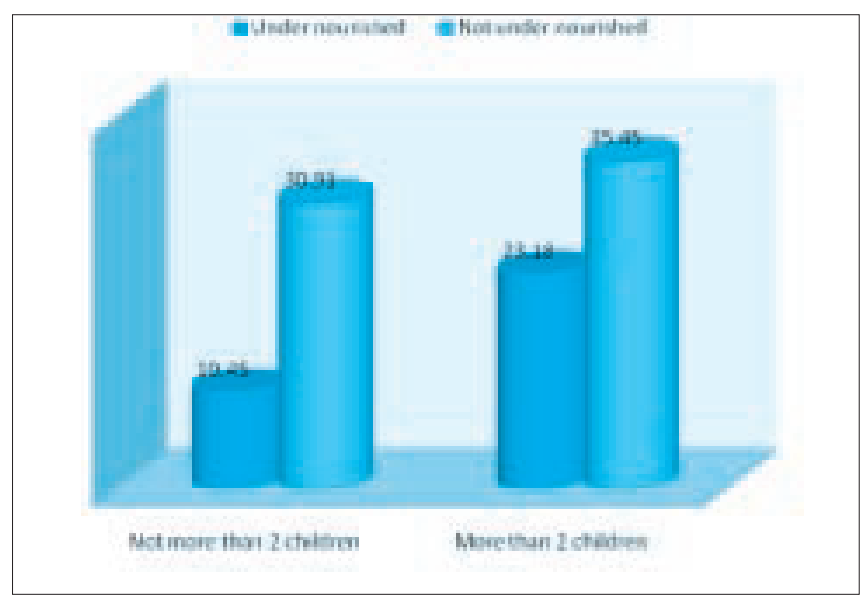

Figure 5 : Association of number of children and nutritional status

More than half (56\%) of the respondents had history of regular use of contraceptives and 19\% used contraceptives irregularly and rest of them (25\%) never used any kind of contraceptive. Among the contraceptive users $61 \%$ used OCP, 21\% used injection and only $3 \%$ had history of using permanent method. Male participation in contraceptive use was only $1 \%$ with condom and about $9 \%$ of the respondents practiced natural methods of contraceptives. The nutritional status of the respondent was measured by BMI. According to WHO guideline BMI $<18.5$ is under weight, 18.5- 24.99 is normal range and $\geq 25$ is defined as over-weight ${ }^{5}$. One-third (34\%) were undernourished, 55\% had normal BMI and only $11 \%$ found overweight. 
The monthly family income was found significantly associated with the nutritional status $(\mathrm{p}<0.05)$. Among the higher income group (>5000 tk.) almost $76 \%$ were not under nourished but only $53 \%$ were not under nourished among the lower income group. Respondents of higher income group showed almost 3 times more likely to be not under nourished than the respondents of lower income group $[\mathrm{OR}=2.7$; 95\% CI $(1.5$ 4.8)]. Educational status of the respondents was not significantly associated with the nutritional status of the respondent $(\mathrm{p}>0.05)$.

The association between early marriage and nutritional status showed no significant association $(\mathrm{P}>0.05)$ but more than onethird of early marriage group were under-nourished. Among the respondents with history of adolescent pregnancy ( $<19$ years) more than one-third were under-nourished whereas only $18.2 \%$ were undernourished among the respondents those had no history of adolescent pregnancy. Adolescent pregnancy and nutritional status was significantly associated $(\mathrm{P}<0.05)$. Respondents without adolescent pregnancy had almost 3 times less likely to be under-nourished than their counter part [OR = 2.7; 95\%CI (1.18-6.15)]. Among the lower parity ( $<2$ children) group $75 \%$ were not under nourished whereas in higher parity ( $>2$ children) group only $60 \%$ were under-nourished. Parity of the respondents was in significant state with nutritional status $(\mathrm{P}<0.05)$. Respondents with lower parity were almost 2 times less likely to be under-nourished than the respondents with higher parity $[\mathrm{OR}=0.51 ; 95 \% \mathrm{CI}(0.28-0.93)]$.

\section{DISCUSSION}

Socio-demographic characteristics were almost similar to the findings of BDHS, 2011 and in few cases it might be varied due to study procedure or regional variation ${ }^{6-9}$. Among the contraceptives user $61 \%$ of the respondent used OCP but only 2 husband $(0.9 \%)$ used condom which is very much consistent with the finding of a study by them ${ }^{10}$. The peek age of their menarche was around the age of 12 years. The mean age of menarche was 12 years with standard deviation (SD) of \pm 0.99 year. Lowest age was 10 years and height was 17 years.
But their peek age at marriage was around 17 years, about $70 \%$ of them got marriage $<18$ years age which is similar to the finding of Bangladesh population and Housing census 2011 ${ }^{11}$. In addition to that, their peek age at $1^{\text {st }}$ pregnancy was also around 17 years; most of them about $80 \%$ got conceived within the age of 20 years. There average age at $1^{\text {st }}$ pregnancy was 18 years which was almost similar to the Bangladesh demographic profile index mundi $2013^{9}$. Average number of living children was 2.95 and $54 \%$ delivery were conducted at home by skilled birth attendants or dai and only $30 \%$ had complication during pregnancy. Bangladesh demographic survey 2013 found 2.5. In this study found a bit higher may be due to its position in coastal area ${ }^{11}$. About 34\% were found undernourished, 55\% had normal BMI and only $11 \%$ found over weight. This finding was comparable with the Child and Mother Nutrition Survey of Bangladesh, $2005^{12}$.

This study revealed nutritional status of respondent significantly associated with monthly family income $(p<0.05)$.Educational status of the respondents was not in significant state with nutritional status of coastal women which was not similar to the findings of other studies ${ }^{13}, 14$. It might be varied due to sample selection procedure or regional variation. Though marital age was not significantly associated with nutritional status but age at first pregnancy and number of children were in significant state with nutritional status $(\mathrm{p}<0.05)$ and it was similar with another study in India ${ }^{15}$.

\section{CONCLUSION}

Reproductive health and nutritional status of women of coastal area were in vulnerability. Socio-demographic disparity was common in variation of nutritional status of women. They were more vulnerable in adolescent pregnancy and early marriage was common. Programs should be taken to reduce socioeconomic inequalities to improve reproductive health and nutritional status of women in coastal area.

\section{DISCLOSURE}

All the authors declared no competing interest.

\section{REFERENCES}

1. Warrick RA, Bhuiya A.H, Mirza M.Q. Climate Change and Sea-level Rise: the Case of the Coast. Briefing Document No. 6 , Bangladesh Unnayan Parishad (BUP), Dhaka. 1993.

2. Side bars for meeting unmet need. Available: http:// www.infoforhealth $\mathrm{Org} / \mathrm{Pr} / \mathrm{J} 43$ bones [accessed on 12.10.2013].

3. Ronsmans C and Graham WJ, "Maternal Mortality: Who, When Where and Why". Lancet. 2006;1189-1200.

4. Brown K. Making Waves: Integrating Coastal Conservation and Development (London: United Nations Environment Programme [UNEP], 2002): 2; and UNEP, Global Environment Outlook 3 (London: UNEP, 2003): 188.

5. WHO expert consultation. HYPERLINK

"http://www.ncbi.nlm.nih.gov/entrez/query.fcgi? cmd=Retrieve\&db=pubmed\&dopt=Abstract\&list_uids=14726171"Appropriate body-mass index for Asian populations and its implications for policy and intervention strategies.HYPERLINK "http://www.ncbi.nlm.nih.gov/entrez/query.fcgi?cmd=Retrieve\&db=pubmed\&dopt=Abstract\&list_uids=14726171" The Lancet. 2004; 157-163.

6. Bangladesh Demographics and Health Survey. National Institute of Population Research and Training (NIPORT) ; 2011.

7. Child and Mother Nutrition Survey of Bangladesh, 2005.

8. Bangladesh progress report 2013 by General Economic Division and Bangladesh Planning Commission, Government of the people's republic of Bangladesh.

9. Bangladesh demographic profile index mundi 2013.

10. Ferdousi SK, Jabbar MA, Hoque SR, Karim SR, Mahmood AR, ARA R, Khan NR. Unmet need of family planning among rural women in Bangladesh. J Dhaka MedColl. 2010; 19(1): 11-15.

11. Bangladesh population and Housing census 2011. Available: http://www.bbs.gov.bd/WebTestApplication/userfiles/Image/BBS/Socio_Economic.pdf. [Accessed on 10.01.2014]

12. Child and Mother Nutrition Survey of Bangladesh, 2005. Available: http://www.unicef.org/bangladesh/Child_and_Mother_Nutrition_Survey.pdf. [Accessed on 10.01.2014].

13. Begum M, "Nutritional status of the adolescent mothers in a rural area of Bangladesh"2013.

14. Idowu O, Ibiyemi O, Wasiu A and Olayinka C. Maternal and child under-nutrition in rural and urban communities of Lagos state, Nigeria: the relationship and risk factors. Published online 2013 July 23. doi: 10.1186/1756-0500-6-286 . PMCID: PMC3725170.

15. Mohammad S, Arokiasamy P.Does Fertility Influence Nutrition? The Emerging Linkages in Low and High Fertility States of India. Annual meeting, Population association in America. 2009. 